\title{
Development of Operand Desorption Gas Analysis System
}

\author{
Hiroki Kurisu, ${ }^{1 *}$ Takayuki Kimura, ${ }^{1}$ Setsuo Yamamoto, ${ }^{1}$ and Tetsuo Higuchi ${ }^{2}$ \\ ${ }^{1}$ Support Laboratory of Nanofabrication in Innovation Center with University-Industry-Public Cooperation, \\ Yamaguchi University, 2-16-1 Tokiwadai, Ube, Yamaguchi 755-8611, Japan \\ ${ }^{2}$ MS Group, SI Sales Promotion Department, Sience and Measurement Instruments Sales Division, JEOL Ltd., \\ 3-1-2 Musashino, Akishima, Tokyo 196-8558, Japan \\ (Received February 19, 2019; accepted April 24, 2019)
}

Keywords: operand measurement, desorption gas, device, gas chromatograph, mass spectrometer

The Support Laboratory of Nanofabrication of Yamaguchi University is a member of the Nanofabrication Platform Consortium in the Nanotechnology Platform Japan. Our laboratory features the desorption gas analysis of materials and devices based on the original vacuum technology in addition to the nanofabrication. In this paper, an operand desorption gas analysis system (apparatus for dynamic thermal desorption spectroscopy), which is one of our gas analysis systems, is explained. The advantage of this system is that it enables a desorption gas analysis of an operating device under an approximately atmospheric pressure ( 0.1 to $0.2 \mathrm{MPa}$ ) using gas chromatography/mass spectrometry, in contrast to a sample placed in a vacuum in a conventional apparatus for thermal desorption spectroscopy. Moreover, two measurement examples (DC electric motor and solar cell) using this operand gas analysis system were described. In the DC motor, the main desorbed gas from the motor behaved similarly to the motor electric power with the occurrence of failure or stop caused by heating. In the solar cell, from the comparison of the temperature dependence between the open circuit voltage and the main desorbed gases from the solar cell, the temperature durability of the sealing part is confirmed to be related to the electron generation efficiency.

\section{Introduction}

The Nanotechnology Platform Japan (NTPJ) is a project supported by the Ministry of Education, Culture, Sports, Science and Technology. Its mission is to establish a reliable research infrastructure (platform) for scientific innovation by the alliance of institutes with cutting edge equipment and research know-how. Yamaguchi University is a member of the Nanofabrication Platform Consortium in the NTPJ. In this platform, the equipment share-use or the nanofabrication service is provided to any researcher, which contributes to solving the urgent problems in science and technology.

The Support Laboratory of Nanofabrication of Yamaguchi University features a desorption gas analysis of materials and devices based on the extremely high vacuum technology in

*Corresponding author: e-mail: kurisu@yamaguchi-u.ac.jp

https://doi.org/10.18494/SAM.2019.2338 
addition to the nanofabrication. Table 1 shows four gas analysis apparatuses of our laboratory, namely, apparatuses for (a) dynamic thermal desorption spectroscopy, (b) highly sensitive thermal desorption spectroscopy, (c) a very small amount of outgassing measurements, and (d) partial pressure analysis in ultrahigh vacuum. These apparatuses enable the analysis of a very small amount of gas by letting the gas analysis component arrive at an ultrahigh vacuum of less than $10^{-6} \mathrm{~Pa}$. In particular, the apparatus for a very small amount of outgassing measurements enables the gas analysis component to arrive at an extremely high vacuum of $10^{-10} \mathrm{~Pa}$ using our original vacuum technology, ${ }^{(1-4)}$ and we carry out our only support for the development of a next-generation electron gun (DC500 kV electron gun). ${ }^{(5)}$ The apparatus for dynamic thermal desorption spectroscopy is characterized by analysis with the desorbed gas from the operating device developed jointly by us and JEOL.

Recently, the operand measurement of the characteristics of a device and a material in operation has attracted considerable attention. This measurement was started by the proposal of the nanomeasurement of devices in a controlled environment, which is named active manipulation, ${ }^{(6,7)}$ and that of the simultaneous measurement of optical measurement and activity, and the selectivity measurement of the reacting catalyst material. ${ }^{(8)}$ In the field of

Table 1

Gas analysis apparatuses of Yamaguchi University in Nanotechnology Platform Japan.

\begin{tabular}{lll}
\hline Apparatus & Maker & Features and Specifications \\
\hline & & Operand measurement of the desorbed gas from devices. \\
& & Parameters: temperature, electric power, light, force \\
(a) $\begin{array}{l}\text { Dynamic thermal } \\
\text { desorption spectroscopy }\end{array}$ & JEOL (customized) & Gas detector: quadrupole mass spectrometer \\
& & Mass range: $m / z 1.5-1022$ \\
& & Resolution: $1 p g($ OFN: $m / z$ 272) $S / N>360$ (RMS) \\
\hline
\end{tabular}
Resolution: 1pg (OFN: $\mathrm{m} / z$ 272) $S / N>360$ (RMS)

(b) Highly sensitive thermal

$\begin{array}{ll}\text { (b) } \begin{array}{l}\text { Gas detector: quadrupole } \\ \text { desorption spectroscopy }\end{array} & \text { In-lab development } \\ & \text { Ultimate pressure: } 10^{-8} \mathrm{~Pa}\end{array}$

Measurement of the thermal desorption gas from materials. Mass range: $m / z$ 1-100, Detection limit: $10^{-11} \mathrm{~Pa}\left(\mathrm{~N}_{2}\right)$

Very small amount of

(c) outgassing measurements In-lab development system
Measurement of the outgassing rate from materials. Gas detector: extremely high vacuum gauge Ultimate pressure: $10^{-10} \mathrm{~Pa}$ (extremely high vacuum) Detection limit: $10^{-12} \mathrm{Pam}^{3} \mathrm{~s}^{-1}$

Remodel the apparatus according to the user's requests. Apparatus for partial

(d) pressure analysis in ultrahigh vacuum
In-lab development Gas detector: quadrupole mass spectrometer Ultimate pressure: $10^{-6} \mathrm{~Pa}$ Mass range: $m / z 1-300$, detection limit: $10^{-9} \mathrm{~Pa}\left(\mathrm{~N}_{2}\right)$

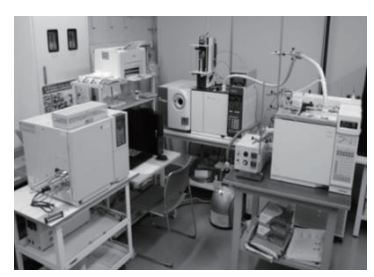

(a)

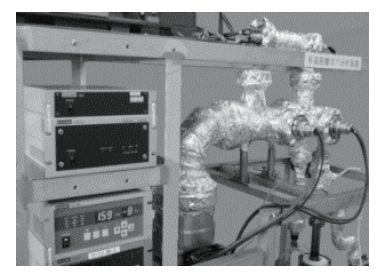

(b)

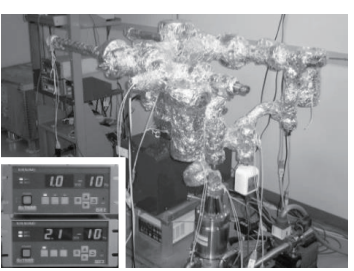

(c)

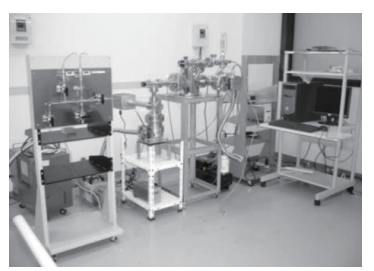

(d) 
surface science and technologies, many studies using an operand measurement of electron spectroscopy, X-ray spectrometry, and scanning probe microscopy have been conducted thus far. $^{(9)}$ An open laboratory characterized by an operand measurement (OPERAND-OIL) was established in 2016. ${ }^{(10)}$ Thus, research and development using an operand measurement is greatly advanced at present. Because a dissolved gas of device materials and a filler gas or a vacuum environment of sealing devices affect device functions, we focus on the operand gas analysis of the devices, and we developed the apparatus for dynamic thermal desorption spectroscopy. In this paper, this operand desorption gas analysis system is introduced and experimental examples are described.

\section{Apparatus for Dynamic Thermal Desorption Spectroscopy}

To analyze the desorbed gas from the operating devices, we developed the apparatus for dynamic thermal desorption spectroscopy. Figure 1 shows the schematic diagram of our apparatus. In a conventional apparatus for thermal desorption spectroscopy, a sample placed in high vacuum is heated by light irradiation from an infrared lamp, and the desorbed gas from the sample is measured using a mass spectrometer. In contrast, in our apparatus, helium gas (carrier gas) is introduced into the sample chamber, and an approximately atmospheric pressure ( 0.1 to $0.2 \mathrm{MPa}$ ), i.e., a device operating pressure, is provided. Here, because it is impossible to introduce a gas of atmospheric pressure to the mass spectrometer operating in high vacuum, gas chromatography/mass spectrometry (GC/MS) is adopted for our apparatus.

The gas analysis method using our apparatus is explained (see Fig. 1). (1) The sample chamber containing a device (sample) is set in the heating apparatus. (2) Helium gas is

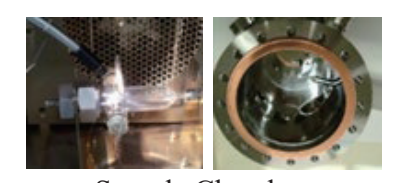

Sample Chamber

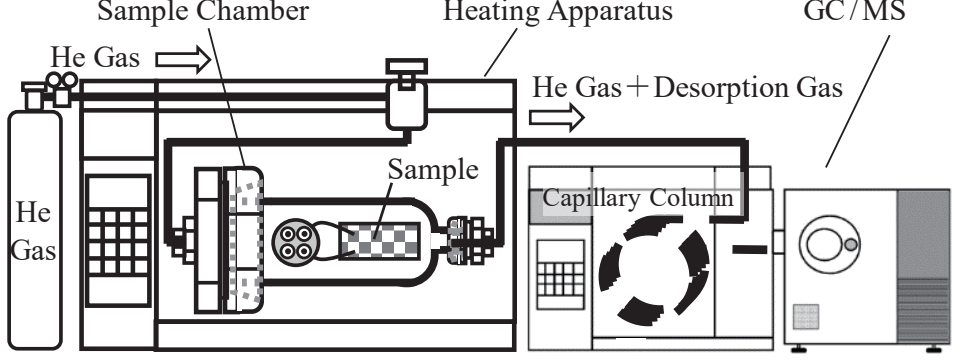

Heating Apparatus

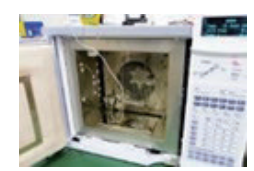

Heating Apparatus

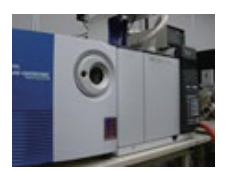

$\mathrm{GC} / \mathrm{MS}$
Gas Chromatography / Mass Spectrometry

(GC/MS)

\begin{tabular}{ll}
\hline \multicolumn{2}{c}{ Specifications } \\
\hline $\begin{array}{l}\text { Sample chamber } \\
\text { Material }\end{array}$ & $\begin{array}{l}\text { Quartz glass, Stainless steel } \\
\text { Size }\end{array}$ \\
& $\begin{array}{l}15 \mathrm{~mm} \phi \times 15 \mathrm{~mm}, \\
98 \mathrm{~mm} \phi \times 100 \mathrm{~mm} \text {, etc. }\end{array}$ \\
\hline Heating apparatus & \\
Size & $300 \times 160 \times 280 \mathrm{~mm}^{3}$ \\
Temperature range & $\mathrm{RT}-450^{\circ} \mathrm{C}$ \\
\hline GC/MS & \\
Gas chromatograph & \\
Capillary column & $250 \mu \mathrm{m} \phi \times 30 \mathrm{~m}$, etc. \\
Temperature range & $\mathrm{RT}-450{ }^{\circ} \mathrm{C}$ \\
Mass spectrometer & \\
Mass range & $m / z \quad 1.5-1022$ \\
Resolution & $1 \mathrm{pg}(\mathrm{OFN}: \mathrm{m} / \mathrm{z} 272)$ \\
(EI mode scan) & $\mathrm{S} / \mathrm{N}>360(\mathrm{RMS})$
\end{tabular}

Fig. 1. (Color online) Schematic diagram of developed apparatus for dynamic thermal desorption spectroscopy. 
introduced into the sample chamber, and the desorbed gas from the sample and helium gas are transferred to a capillary column attached to the gas chromatograph, where the sample is heated and/or operated, and the gas desorption from the sample is accelerated. (3) The flow rate of the mixed gases of helium gas and the desorption gas that passed through the capillary column is very low $\left(10^{-6}-10^{-4} \mathrm{Pam}^{3} \mathrm{~s}^{-1}\right)$, and then these gases are introduced to the mass spectrometer and measured. The component of the apparatus is described (see Fig. 1). Sample chambers of various sizes, e.g., $15 \mathrm{~mm} \phi \times 15 \mathrm{~mm}, 20 \mathrm{~mm} \phi \times 100 \mathrm{~mm}$, and $98 \mathrm{~mm} \phi \times 100 \mathrm{~mm}$, made of quartz glass or stainless steel were prepared. In the sample chamber made of quartz glass, the introduction and derivation of light are possible. Multipin electrical feedthroughs were attached to the sample chamber to carry out device operation or measure a device signal. In the other sample chamber, the needle-formed linear feedthrough was attached to introduce a force to the sample. In the heating apparatus (MSTD258M-A, GL Science), the inner size is $300 \times 160 \times$ $280 \mathrm{~mm}^{3}$ and the heating temperature ranges from RT to $450{ }^{\circ} \mathrm{C}$. In the gas chromatograph of GC/MS (JMS-Q1050, JEOL), various types of capillary columns can be attached, and temperature ranges from RT to $450{ }^{\circ} \mathrm{C}$. The mass spectrometer is of the quadrupole type, its mass range is $\mathrm{m} / \mathrm{z}$ from 1.5 to 1022 , and the resolution is $S / N>360$ [octafluoronaphthalene (OFN): $\mathrm{m} / \mathrm{z} 272$ ] of $1 \mathrm{pg}$ obtained by scan measurement in the electric ionization mode.

\section{Example of Operand Measurement}

As an example of the device gas analysis using the apparatus for dynamic thermal desorption spectroscopy, operand measurements for the DC electric motor and solar cell are described.

\subsection{DC electric motor}

The small DC electric motor (size: $38.0 \times 20.0 \times 16.5 \mathrm{~mm}^{3}$ ) was installed in the sample chamber, and for motor driving, a rated voltage (DC $1.5 \mathrm{~V}$ ) was supplied through the electric feedthrough from the outside as shown in Fig. 2(a). The sample chamber was set into the heating apparatus and heated from RT to $100{ }^{\circ} \mathrm{C}$, and its temperature $\left(100{ }^{\circ} \mathrm{C}\right)$ was kept for $30 \mathrm{~min}$. The desorbed gas from the motor was introduced into GC/MS by helium gas and measured. Here, a blank tube $(250 \mu \mathrm{m} \phi \times 30 \mathrm{~m})$ was used as the capillary column.

Figure 2(b) shows the mass spectrum $(\mathrm{m} / \mathrm{z} 20-100)$ of the desorbed gas from the sample without motor driving at RT. Small amounts of residual gases such as $\mathrm{N}_{2}$ or CO gas $(\mathrm{m} / \mathrm{z} 28)$ and $\mathrm{CO}_{2}$ gas $(\mathrm{m} / \mathrm{z} 44)$ were measured. Peaks appeared at $\mathrm{m} / \mathrm{z} 26,27,28,39,41$, and 50 on the mass spectrum with motor driving at RT as shown in Fig. 2(c). These peaks were estimated to originate from the aromatic series-based organic materials used in the bearing or brush of the motor. Many peaks appeared at $m / z>40$ with motor driving at $100{ }^{\circ} \mathrm{C}$ as shown in Fig. 2(d). These peaks result from the grease of the motor, because they are similar to the peaks observed on the mass spectrum of the thermally desorbed gas from the heated grease of the motor.

The thermal desorption gas of the motor during driving was measured, and at the same time, the input voltage $[V(\mathrm{~V})]$ and electric current $[I(\mathrm{~A})]$ to the motor were monitored to observe the driving status of the motor. Figure 3 shows time changes in the drive electric power $(I \times V)$ 

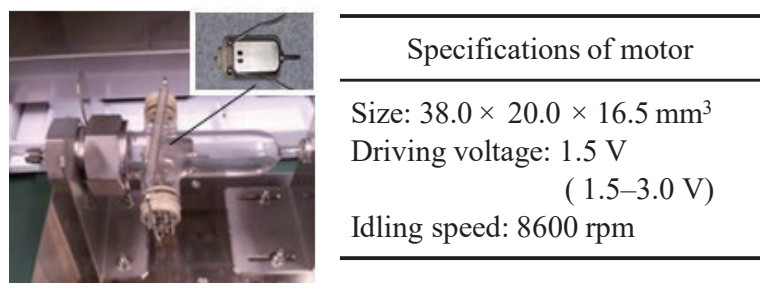

(a)

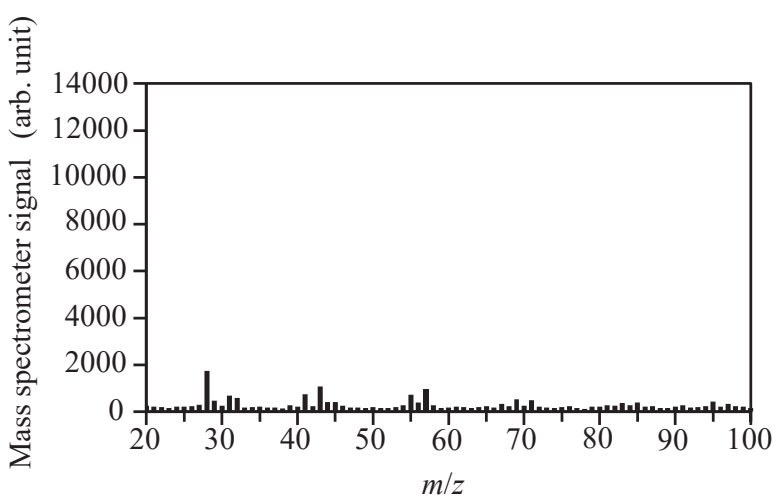

(b)

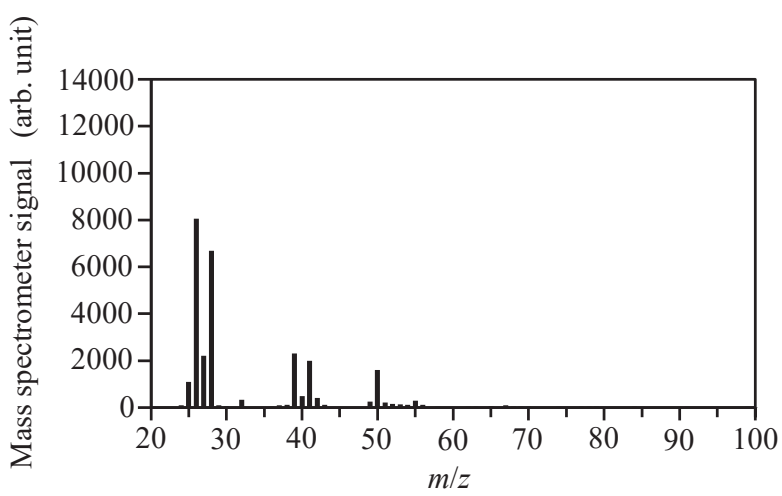

(c)

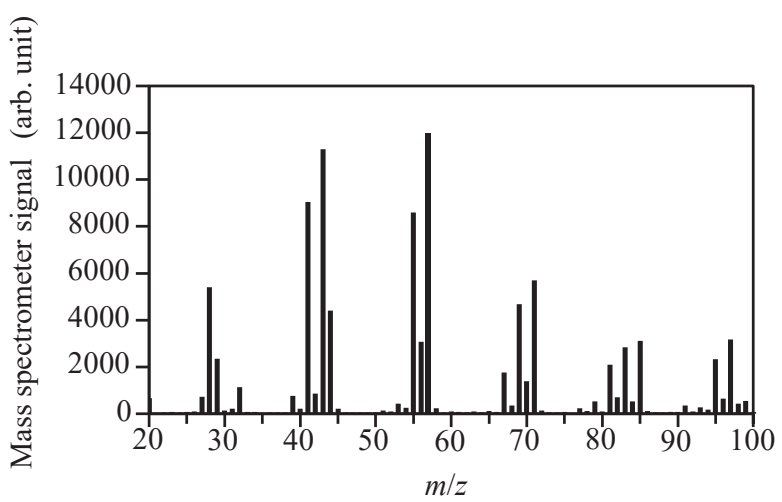

(d)

Fig. 2. (Color online) (a) Photograph of the DC motor set in the sample chamber and specifications of the motor, and (b) the mass spectrum $(m / z 20-100)$ of the desorbed gas from the sample without motor driving at RT, (c) that with motor driving at RT, and (d) that with motor driving at $100{ }^{\circ} \mathrm{C}$.

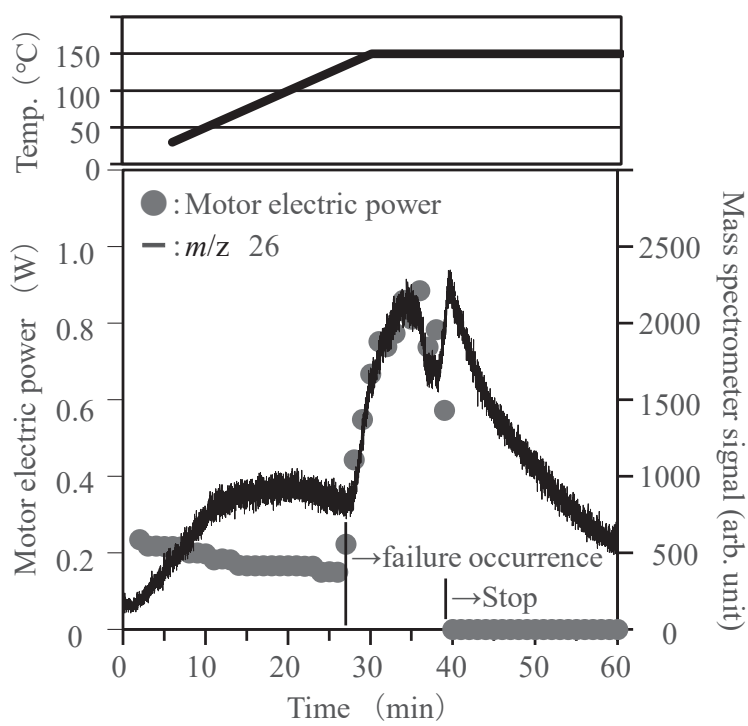

Fig. 3. Time changes in the motor electric power and the mass spectrometer signal of the main desorbed gas $(\mathrm{m} / \mathrm{z}$ 26) during motor driving. Time profile of the temperature in the top view. 
and the mass spectrometer signal of the main desorption gas $(\mathrm{m} / \mathrm{z} 26)$ during motor driving. ${ }^{(11)}$ Here, the temperature was increased from RT to $150{ }^{\circ} \mathrm{C}$ for $30 \mathrm{~min}$ and was kept at $150{ }^{\circ} \mathrm{C}$ up to $60 \mathrm{~min}$ as shown in the top view of Fig. 3. Up to $120^{\circ} \mathrm{C}$, the motor electric power slightly decreased, and the mass spectrometer signal of the desorption gas increased from RT to $50{ }^{\circ} \mathrm{C}$ and showed a plateau from 50 to $120{ }^{\circ} \mathrm{C}$. The drive electric power suddenly increased at $120{ }^{\circ} \mathrm{C}$ (27 min) and became about fourfold the rating electric power. It is considered that the failure due to the heating of the motor occurred at this time, and after 40 min (constant at $150{ }^{\circ} \mathrm{C}$ ), the motor showed $0 \mathrm{~W}$ and completely stopped. Depending on the change in motor electric power, the quantity of desorbed gas increased and formed two desorption peaks. The first desorption peak is caused by the failure due to the heating, and the second peak is caused by the friction of the motor stop. After the stop, the desorption gas gradually decreased.

\subsection{Solar cell}

An amorphous silicon solar cell (A or B with similar specifications) was set in the sample chamber in the heating apparatus as shown in Fig. 4(a). The solar cell generated electricity

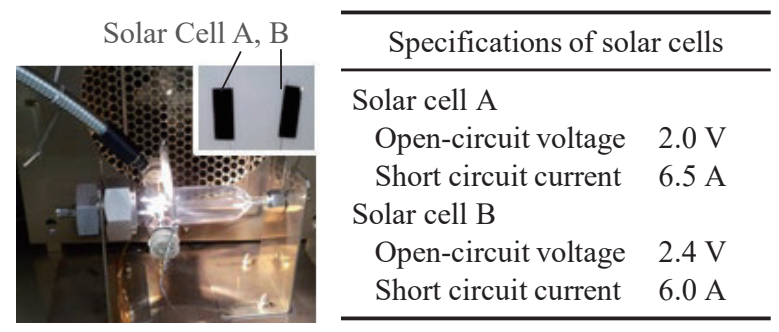

(a)

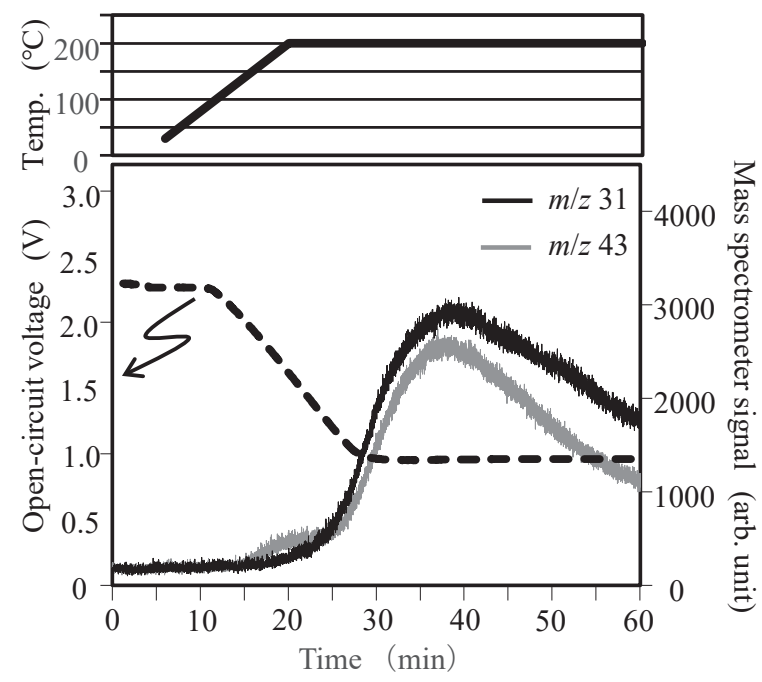

(b)

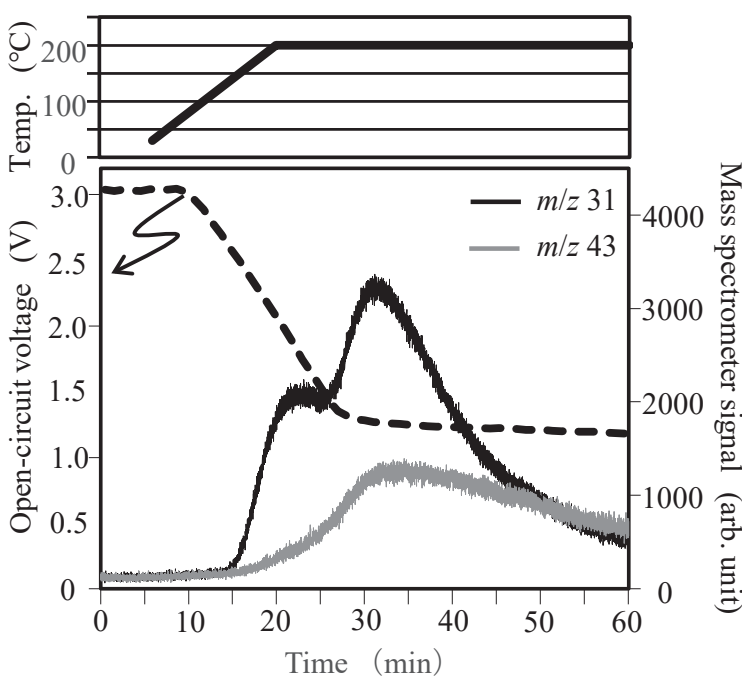

(c)

Fig. 4. (Color online) (a) Photograph of the solar cell set in the sample chamber and specifications of solar cells A and $\mathrm{B}$, and time changes in the open-circuit voltages and mass spectrometer signals of the main desorbed gases $(\mathrm{m} / \mathrm{z}$ 31 and 43) during the electric generation of (b) solar cell A and (c) solar cell B. 
through light irradiation from a halogen lamp from the outside and heated from RT to $200{ }^{\circ} \mathrm{C}$ in $10{ }^{\circ} \mathrm{C} / \mathrm{min}$, and its temperature $\left(200{ }^{\circ} \mathrm{C}\right)$ was kept up to $60 \mathrm{~min}$ as shown in the top view of Fig. 4(b). The desorption gas and open-circuit voltage of the solar cell were measured.

Figures 4(b) and 4(c) show the measurement results of solar cells A and B, respectively. Here, $m / z 31$ and 43 indicate the specific desorbed gases from the solar cell. The open-circuit voltages of the two samples decreased with increasing temperature and became $50 \%$ at $200{ }^{\circ} \mathrm{C}$ (27 min). This reduction is explained by the temperature dependence of $0.3 \% /{ }^{\circ} \mathrm{C}$ for the opencircuit voltage of the amorphous silicon solar cell; therefore, this behavior is not due to the occurrence of the failure of the solar cell. From 27 to $60 \mathrm{~min}$ (constant at $200{ }^{\circ} \mathrm{C}$ ), the opencircuit voltage of solar cell A did not change; on the other hand, that of solar cell B slightly decreased. These results suggest that the electric generation efficiency of solar cell A did not change and that of solar cell B deteriorated with heating at $200^{\circ} \mathrm{C}$.

The desorption gases $(\mathrm{m} / \mathrm{z} 31,43)$ of solar cell A increased from $25 \mathrm{~min}$ (constant at $200{ }^{\circ} \mathrm{C}$ ) and the desorption peak appeared at $40 \mathrm{~min}$, whereas those $(\mathrm{m} / \mathrm{z} 31,43)$ of solar cell B increased from 15 min $\left(150{ }^{\circ} \mathrm{C}\right)$ with increasing temperature and the peak was observed 32 min later. Because these gases originate from the adhesive between the protective film and the solar device, it was found that the temperature durability of the sealing part of solar cell A is higher than that of solar cell B. It is considered that the difference in this temperature durability causes no change in the electric generation efficiency of solar cell A but deteriorates that of solar cell B with heating.

\section{Conclusions}

In this paper, an operand desorption gas analysis system named the apparatus for dynamic thermal desorption spectroscopy was explained, and two measurement examples (DC electric motor and solar cell) were described. By using this operand gas analysis system, the durability for heat and the environment of the device were evaluated, and device life and trouble analyses became possible. In our support of the Nanotechnology Platform Japan, this operand desorption gas analysis system is used effectively for the research and development of various devices such as MEMS devices and gas or vacuum sealing devices.

\section{References}

1 H. Kurisu, T. Muranaka, N. Wada, S. Yamamoto, M. Matsuura, and M. Hesaka: J. Vac. Sci. Technol. A 21 (2003) L10.

2 H. Kurisu, S. Yamamoto, M. Matsuura, T. Morimoto, and M. Hesaka: J. Vac. Soc. Jpn. 50 (2007) 41.

3 H. Kurisu, K. Ishizawa, S. Yamamoto, M. Hesaka, and Y. Saito: J. Phys. Conf. Ser. 100 (2008) 092002.

4 M. Takeda, H. Kurisu, S. Yamamoto, H. Nakagawa, and K. Ishizawa: Appl. Surf. Sci. 258 (2011) 1405.

5 M. Yamamoto, T. Miyajima, T. Uchiyama, and M. Kobayashi: NanotechJapan Bull. 7 (2014). https://www. nanonet.go.jp/ntjb_pdf/nanotechEXPRESS-35.pdf

6 D. Fujita: Materia 41 (2002) 623.

7 D. Fujita, M. Kitahara, K. Onishi, and K. Sagisaka: Nanotechnology 19 (2008) 025705.

8 M. A. Bañares: Catal. Today 100 (2005) 71.

9 Curr. Top. Vac. Surf. Sci. 62 (2019) 3-38.

10 OPERAND-OIL: https://unit.aist.go.jp/operando-oil/

11 H. Kurisu, T. Kimura, and S. Yamamoto: Kinzoku 87 (2017) 1003. 


\section{About the Authors}

Hiroki Kurisu received his M.S. and Ph.D. degrees from Osaka City University, Japan, in 1989 and 1993, respectively. From 1993 to 2003, he was a research associate at Yamaguchi University, Japan. Since 2003, he has been an associate professor at Yamaguchi University. His research interests are in vacuum science and technology. (kurisu@yamaguchi-u.ac.jp)

Takayuki Kimura received his B.S. degree from Tokyo University of Agriculture and Technology, Japan, in 1968. From 1968 to 2010, he worked at the research and development division of Ube Industries, Ltd. Since 2012, he has been a technical support staff (expert) at Yamaguchi University. His research interests are in inorganic chemistry and instrumental analysis. (takayuki@yamaguchi-u.ac.jp)

Setsuo Yamamoto received his M.S. and Ph.D. degrees from Tohoku University, Japan, in 1981 and 1985, respectively. From 1985 to 1992, he was a research associate at Tohoku University, Japan. From 1992 to 2004, he was an associate professor at Yamaguchi University, Japan. Since 2004, he has been a professor at Yamaguchi University. His research interests are in magnetic devices and MEMS. (yamamoto@yamaguchi-u.ac.jp)

Tetsuo Higuchi received his B.S. degree from Tokyo Denki University, Japan, in 1974. From 1974 to 2001, he worked at the analytic instrument division of JEOL Ltd.. He received his Ph.D. degree from Tokyo University of Agriculture and Technology, Japan, in 2001. Since 2008, he has been the president of Hiss lab. His research interests are in instrumental analysis and bioengineering. (tehiguch@jeol.co.jp) 